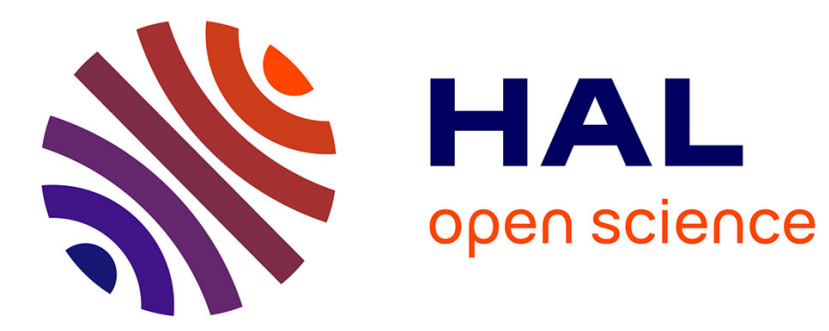

\title{
Continuous-wave scanning terahertz near-field microscope
}

Jean-Paul Guillet, Laurent Chusseau, R. Adam, T. Grosjean, A. Pénarier, F.I. Baida, D. Charraut

\section{- To cite this version:}

Jean-Paul Guillet, Laurent Chusseau, R. Adam, T. Grosjean, A. Pénarier, et al.. Continuous-wave scanning terahertz near-field microscope. Microwave and Optical Technology Letters, 2011, 53 (3), pp.580-582. 10.1002/mop.25754 . hal-00565014

\section{HAL Id: hal-00565014 https://hal.science/hal-00565014}

Submitted on 5 May 2021

HAL is a multi-disciplinary open access archive for the deposit and dissemination of scientific research documents, whether they are published or not. The documents may come from teaching and research institutions in France or abroad, or from public or private research centers.
L'archive ouverte pluridisciplinaire HAL, est destinée au dépôt et à la diffusion de documents scientifiques de niveau recherche, publiés ou non, émanant des établissements d'enseignement et de recherche français ou étrangers, des laboratoires publics ou privés.

\section{(c)(1)}

Distributed under a Creative Commons Attribution| 4.0 International License 
CONTINUOUS-WAVE SCANNING TERAHERTZ NEAR-FIELD MICROSCOPE

\author{
J.-P. Guillet, ${ }^{1}$ L. Chusseau, ${ }^{1}$ R. Adam, ${ }^{1}$ T. Grosjean, ${ }^{2}$ \\ A. Penarier, ${ }^{1}$ F. Baida, ${ }^{2}$ and D. Charraut $^{2}$ \\ ${ }^{1}$ Institut d'Électronique du Sud, UMR 5214 CNRS, Université \\ Montpellier 2, Place E. Bataillon, 34095 Montpellier, France; \\ Corresponding author: chusseau@univ-montp2.fr \\ 2 Institut FEMTO-ST, dept. LOPMD, UMR 6174 CNRS, Université \\ de Franche-Comté, Route de Gray, 25030 Besançon, France
}

ABSTRACT: A versatile cw measurement setup for terahertz near-field reflectometry is proposed. Propagation, coupling, and focusing of wire guided modes are used to achieve a $\lambda / 33$ resolution while imaging a metal corner deposited on glass. The setup is source and detector independent owing to wave coupling and decoupling with differential phase plates.

Key words: near-field scanning microscopy; Terahertz and submillimeter equipment; near-filed imaging probe; Sommerfeld waves

\section{INTRODUCTION}

Near-field imaging is a key technique for high-resolution imaging. This is especially valuable in the terahertz $(\mathrm{THz})$ range where the very long wavelength has a disastrous influence of the far-field imaging resolution limit. Besides the revamping of scanning near-field optical microscopy in the $\mathrm{THz}$ range, original systems taking benefit from Sommerfeld waves (SW) on bare metal rods [1] have been recently developed [2, 3] because such waves have been demonstrated to be efficiently guided with low losses and almost no dispersion [4-6].

Aiming at developing $\mathrm{cw}$ near-field imaging with versatile $\mathrm{THz}$ sources, we already showed the SW excitation with a differential phase element (DPE) and the longitudinal field concentration and selectivity at the apex of a tapered needle [3]. Awad et al. [2] showed separately that such a needle might provide large subwavelength resolution up to the $\mu \mathrm{m}$ scale. In this work, we carefully analyze the propagation of SW on stainless steel rods. By combining them with a Y-splitter (as initially proposed by Mittleman $[4,6]$ ) and by connecting a metallic needle and two DPE at the three end facets of the systems (as shown in Fig. 1), we propose an original and versatile configuration that transposes cw reflection-mode scanning near-field microscope [7] to $\mathrm{THz}$ frequencies. Like optical setups, this system has the

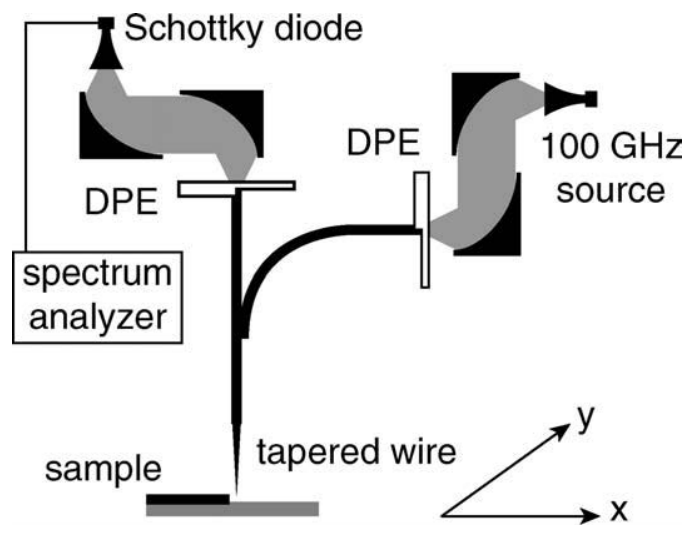

Figure 1 Near-field experimental setup

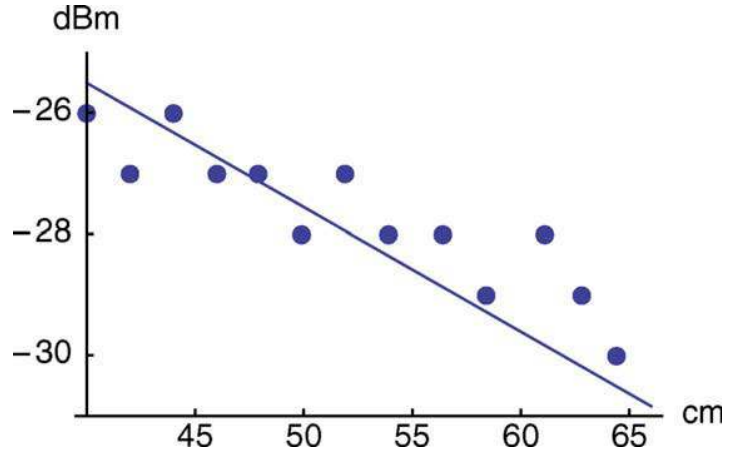

Figure 2 Measured losses vs propagation length. Dark blue circle, measurements; linear fit. [Color figure can be viewed in the online issue, which is available at wileyonlinelibrary.com]

advantage to be coupled with external sources and detectors via linearly polarized freely propagating waves.

\section{SYSTEM DESIGN}

\subsection{Propagation and Coupling Losses}

The proposed $\mathrm{THz}$ microscope system involves the coupling and propagation of SW along metallic wires that we already showed using a set of two parabolic mirrors and a Teflon DPE [3]. The DPE induces a $\pi$-phase difference on half the input beam crosssection so that it efficiently overlaps with the radially polarized wire mode. From the known theoretical field profiles [1], we numerically estimated a coupling efficiency of $\sim 35 \%$ for an input Gaussian beam of waist $\sim 11 \mathrm{~mm}$. To optimize the system design, we conducted preliminary experiments to evaluate the various source of losses. SW excitation is obtained with a microwave synthesizer followed by a $75-110 \mathrm{GHz}$ sextupler electronic source from Spacek Labs Inc delivering $\sim 0 \mathrm{dBm}$ to a rectangular horn antenna. The linearly polarized beam is focused and transformed into SW using two off-axis parabolic mirrors and a DPE. The detection is ensured by a similar quasioptical system in front of the rectangular horn antenna coupled to a Schottky diode and a microwave spectrum analyzer. With acceptable settings of the spectrum analyzer, the noise detection level of the overall detection is estimated to $-80 \mathrm{dBm}$. Stainless steel wires of $0.8 \mathrm{~mm}$ diameter and of known bulk resistivity $1.32 \times 10^{6} \Omega^{-1} \mathrm{~m}^{-1}$ are placed in-between the two DPE couplers of diameter $6 \mathrm{~cm}$. DPEs also serve as wire holders eventually supplemented by a Teflon disk of same diameter if long wires are considered. Emission and detection systems, including DPE and horn antennas, are cross-polarized to reduce any direct coupling. Additionally, an absorbing diaphragm with a clear aperture of $3 \mathrm{~cm}$ is used to cancel any direct transmission between horns while keeping a theoretical transmission in excess of $90 \%$ for the SW. This was verified by measurements without the wire. Propagation losses are thus obtained from successive cutback experiments applied to the wire length from 65 to 40 $\mathrm{cm}$. Results given in Figure 2 show a linear decrease of the transmission according to propagation losses of $0.2 \mathrm{~dB} / \mathrm{cm}$. This slope is important when compared with previous measurements on gold wires [4] and is actually five times larger than the 0.04 $\mathrm{dB} / \mathrm{cm}$ expected from the theory. We have no clear explanation for this discrepancy except wire surface oxidation or contamination with organic materials that might have induced excess losses in combination with the low $\sim 1 \mu \mathrm{m}$ skin depth. From the $-26 \mathrm{dBm}$ transmission at the shorter $40 \mathrm{~cm}$ length and the knowledge of the $-8 \mathrm{dBm}$ direct horn-to-horn transmission 


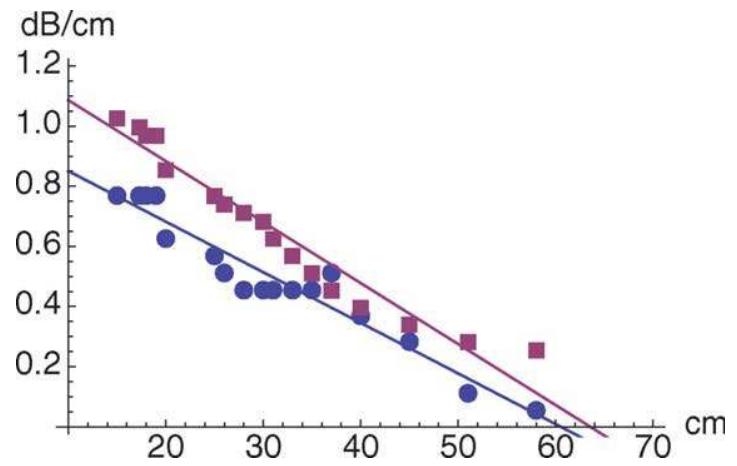

Figure 3 Measured bending losses vs the curvature radius. Blue circle, stainless steel $0.8 \mathrm{~mm}$ diameter; violet square, tungsten $5 \mathrm{~mm}$ diameter. [Color figure can be viewed in the online issue, which is available at wileyonlinelibrary.com]

between source and detector, we estimate the transmission provided by each DPE coupler to $-5 \mathrm{~dB}$, i.e., $\sim 32 \%$. This value is very close to the calculated one and emphasizes the efficiency of this coupling method.

\subsection{Bending Losses}

Bending losses are evaluated with the same setup. We use the natural flexibility of metals by increasing the angle between emission and detection to progressively bend the wires. Figure 2 reports the measured losses per unit length of two wires with different metal nature and diameters. This procedure is different from that used in Refs. 6 and 8, but it produces very similar results. Note that bending radius below $15 \mathrm{~cm}$ are unattainable without inducing permanent distortion of the wire, and large radius $=60 \mathrm{~cm}$ are also impossible because they cannot be distinguished from the natural bending of the wire induced by its own weight. We see in Figure 3 that losses are nearly metal independent, as suggested in [6], because calculations show that the differences between the two experimental curves are most likely due to the different wire radius than to the metal nature.

\subsection{Overall Microscope Losses}

In the final microscope of Figure 1, we found necessary to introduce a right angle between source and detector to cancel the direct coupling due to sample specular reflection. It results in a $90^{\circ}$ bend of $20 \mathrm{~cm}$ radius on one wire that induces a $\sim 30 \mathrm{~dB}$

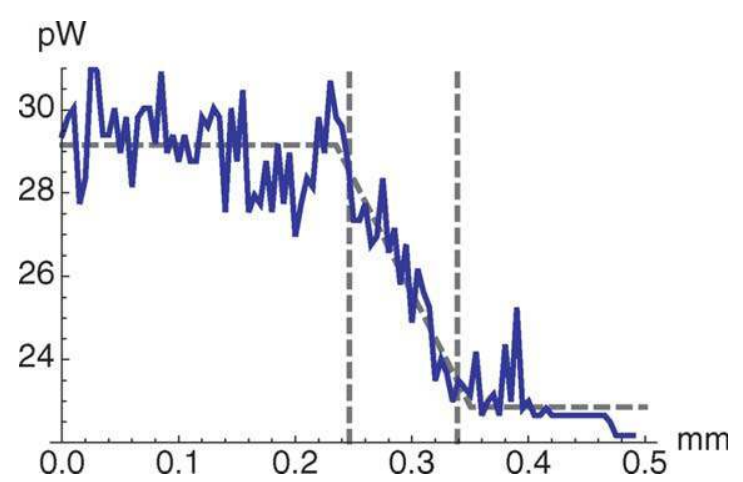

Figure 4 Near-field measurement of a metallic step deposited on glass. - measurement; - - - measurement piecewise approximation and resolution. [Color figure can be viewed in the online issue, which is available at wileyonlinelibrary.com]

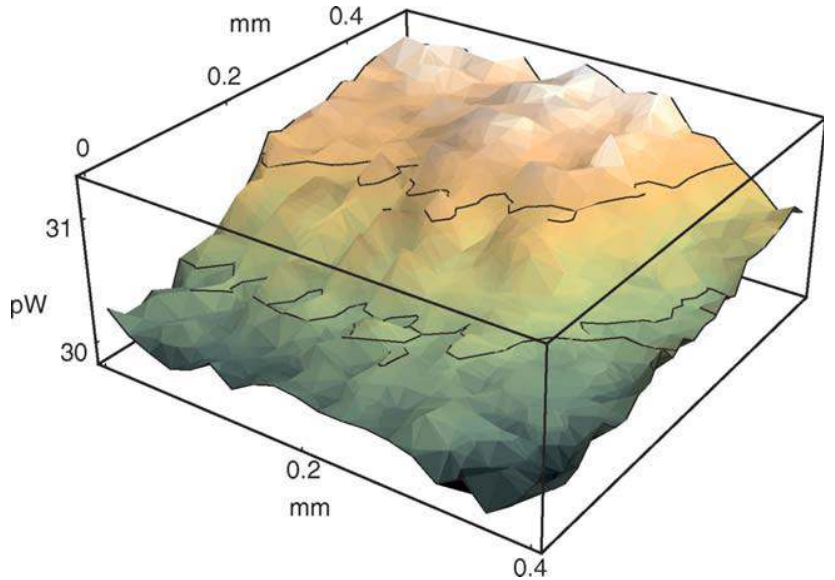

Figure 5 3D image map of the metal right angle corner deposited on glass. [Color figure can be viewed in the online issue, which is available at wileyonlinelibrary.com]

attenuation. One must also account for $\sim 10 \mathrm{~dB}$ losses along the straight wires and the $10 \mathrm{~dB}$ losses of the two DPE couplers. Therefore, even with a perfect Y-splitter and an adiabatic focusing needle, attenuations larger than $50 \mathrm{~dB}$ are expected during image acquisition.

\section{NEAR-FIELD MEASUREMENT}

To complete the final setup of Figure 1, we mechanically attach a 4-cm-long metal needle to one end of the Y-splitter. Needle diameter fits that of the wire and its end is tapered over a distance of $5 \mathrm{~mm}$ up to a spike with a $50 \mu \mathrm{m}$ radius of curvature. This sharp end thus operates as a near-field probe sensitive to the longitudinal electric field [2, 3]. The sample is rasterscanned right beneath the needle apex using two motorized translation stages, and the probe height is adjusted before the scan with a manual translation stage of micrometer resolution. No active height control is applied during scans.

Imaging properties and resolution ability of our setup is tested by scanning one metal $(\mathrm{Au})$ right angle corner deposited on glass substrate. For an estimated $\sim 10 \mu \mathrm{m}$ flyover distance, a 1D scan obtained with a $5 \mu \mathrm{m}$ linear step is given in Figure 4, and a 2D image obtained over a $20 \times 20 \mu \mathrm{m}^{2}$ mesh is given in Figure 5 . The linear scan exhibits a piecewise evolution with a linear transition from the upper level (probe over the metal) to the lower level (probe over the glass substrate). The transition between both occurs over a distance of $90 \mu \mathrm{m}$ (10 to $90 \%$ edge criterion). This value corresponds to $\lambda / 33$ and is close to the $50 \mu \mathrm{m}$ characteristic size of the needle apex. The measured varying signal then comes from the near-field and corresponds to the detection of the longitudinal electric-field component $[2,3]$. This was confirmed by calculating from the theoretical field profiles [1], a $660 \mu \mathrm{m}$ radial field extension at $-3 \mathrm{~dB}$ for a $50 \mu \mathrm{m}$ diameter stainless steel wire. As a consequence, any variation in the detected signal that may originate from the radial field component would have extended over more than the spans used in experiments and just produced an increase of the background. The 2D image of Figure 5 shows the ability of the setup to map planar objects with the same features. Similar spatial resolutions are roughly obtained in both dimensions although scan steps are four times larger.

\section{CONCLUSIONS}

We have built a versatile $\mathrm{cw}$ measurement setup for terahertz nearfield reflectometry with $\lambda / 33$ resolution. Both measurement 
examples show a detected power of only $\sim 30 \mathrm{pW}$ (i.e., $-75 \mathrm{dBm}$ ) very close to the detection background level. As characterized, most of the losses come from the wire bending. Changing the geometry in next evolutions of the setup can eventually reduce them efficiently. Improvements are also expected both in resolution and sensitivity by using sharper needles for which high electric field enhancements are expected in the near-field [8].

\section{ACKNOWLEDGMENT}

The authors acknowledge the French National Research Agency for funding under grant TERASCOPE, \#ANR-06-BLAN-0073.

\section{REFERENCES}

1. G. Goubau, Surface waves and their application to transmission lines, J Appl Phys 21 (1950), 1119-1128.

2. M. Awad, M. Nagel, and H. Kurz, Tapered Sommerfeld wire terahertz near-field Imaging, Appl Phys Lett 94 (2009), 051107.

3. R. Adam, L. Chusseau, T. Grosjean, A. Penarier, J.-P. Guillet, and D. Charraut, Near-field wire-based passive probe antenna for the selective detection of the longitudinal electric field at terahertz frequencies, J Appl Phys 106 (2009), 073107.

4. K. Wang and D. Mittleman, Metal wires for terahertz wave guiding, Nature 432 (2004), 376-379.

5. T. Jeon, J. Zhang, and D. Grischkowsky, THz Sommerfeld wave propagation on a single metal wire, Appl Phys Lett 86 (2005), 161904.

6. K. Wang and D. Mittleman, Guided propagation of terahertz pulses on metal wires, J Opt Soc Am B 22 (2005), 2001-2008.

7. P.M. Adam, P. Royer, R. Laddada, and J.L. Bijeon, Polarization contrast terahertz-near-field imaging of anisotropic conductors, Ultramicroscopy 71 (1998), 327-331.

8. V. Astley, J. Scheiman, R. Mendis, and D.M. Mittleman, Bending and coupling losses in terahertz wire waveguides, Opt Lett 35 (2010), 553-555. 